\title{
Some Investigations into the Electrical Discharge Machining of Inconel 718 Alloy using Copper and Brass Electrodes
}

\author{
S. Kale $^{1 \star}$, D. Khedekar ${ }^{2}$, P. Brahmankar ${ }^{3}$ and M.Sadaiah ${ }^{4}$ \\ ${ }^{1}$ P.G. Student, Jawaharlal Nehru Engineering College, Aurangabad, India \\ ${ }^{2}$ Asso. Prof., Jawaharlal Nehru Engineering College, Aurangabad, India \\ ${ }^{3}$ Prof. and head Dr. Babasaheb Ambedkar Technological University, Lonere, India \\ ${ }^{3}$ Asso. Prof., Dr. Babasaheb Ambedkar Technological University, Lonere, India \\ \{somnathkale.mechanical@gmail.com\}
}

\begin{abstract}
Electric discharge machining (EDM) is a non-traditional machining process; it is a well established machining option in many manufacturing industries throughout the world. There are no physical cutting forces between the tool and work piece while removing the material, it only uses thermal energy to machine electrically conductive parts regardless of hardness has been its distinctive advantage in the manufacturing industries. Inconel 718 is one of the alloy that have relatively poor machinability, due to its work hardening nature, retention of high strength at high temperature and low thermal conductivity. This paper presents the results of experimental work carried out in electrical discharge machining of Inconel 718 using two different tool materials namely copper and brass. The outline of this work is to optimize the process parameters like current, voltage and pulse on time for maximum material removal rate and minimum tool wear rate. The response surface analysis is used for the data analysis while RSM's D-optimal method is used to solve the multi response optimization. It is observed that copper electrode perform better than brass for the tested work material.
\end{abstract}

Keywords : EDM, Material removal rate, RSM, Tool wear rate

\section{Introduction}

The recent developments in the field of EDM have progressed due growing application of EDM process, it is used to do the machining of new materials that are hard and difficult to machine, such as tool steels, super alloys, heat resistant steels etc. used in aerospace, aeronautics and nuclear industries. These materials also find applications in other industries because of their high strength to weight ratio, hardness and heat resisting qualities[1-3]. In EDM material is removed from the conductive material through the action of an electrical discharge of short duration and high current density between tool and workpiece. The material is removed from the workpiece through the action of erosion. The main disadvantages of electrical discharge machining are, it is time consuming and higher cost. So researchers focus their attention to reduce the cost [1]. Inconel 718 is a precipitation-hardened nickel-chromium alloy, so it is important to improve the process capabilities of EDM for machining of Inconel 718 and fix the appropriate range of selected variables for machining. In this work material removal rate and tool wear rate are considered for the performanance of EDM. Experiments were carried out with copper and brass electrodes of diameter $10 \mathrm{~mm}$, and analyzed for their adaptability to this material [2]. The main purpose of this work is to compare the machinability of copper and brass electrode and find out the most suitable electrode for machining of Inconel 718. Machining parameters optimization has been carried out through response surface methodology, utilizing the relevant experimental data and optimum values of input parameters were found using RSM's D-optimal method. The adequacy of developed mathematical model has also been tested by analysis of variance test.

\section{Experimental Method and Procedure}

All the experiments where performed on die sinking 'ZNC-50 ELECTRONICA EDM' machine. The EZNC has the provisions of programming in the Z-vertical axis control and manually operating $\mathrm{X}$ and $\mathrm{Y}$ axes.

For the experimentation purpose "RUST LICK-30" oil having dielectric strength $45 \mathrm{~kW}$ was used as a dielectric medium. A jet flushing system is used in order to assure the adequate flushing of debris from the gap zone was employed.

Two electrodes, copper and brass of diameter $10 \mathrm{~mm}$ were used for the machining. The diameter of electrode was measured with micrometer (LC 0.01) and its initial mass was measured with weighing machine. The

B. Iyer, S. Nalbalwar and R.Pawade (Eds.)

ICCASP/ICMMD-2016.Advances in Intelligent Systems Research.

Vol. 137, Pp. 819-824.

(C) 2017- The authors. Published by Atlantis Press

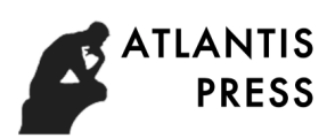

This is an open access article under the CC BY-NC license (http://creativecommons.org/licens)es/by-nc/4). 
workpiece samples of Inconel 718 are used in the experiments were plates of following dimensions: $(90 \times 20 \times 3.15) \mathrm{mm}$. The chemical composition of workpiece and physical properties of tool materials is given in table 1 and table 2 respectively. A depth of cut of $3.15 \mathrm{~mm}$ was set for the machining of all the workpiece samples. Finally the required power switches were switched 'ON' for operating the desired input values. After the machining operation, the electrode and workpiece were taken out and weighed again. The operational time was measured by using stop watch for each hole. The same experiments were performed for all the input parameters settings.

Table 1 Chemical Composition of Workpiece

\begin{tabular}{|c|c|c|c|c|c|c|c|}
\hline Element & $\mathrm{Ni}+\mathrm{Co}$ & $\mathrm{Cr}$ & $\mathrm{Fe}$ & $\mathrm{Nb}+\mathrm{Ta}$ & $\mathrm{Mo}$ & $\mathrm{Ti}$ & $\mathrm{Al}$ \\
\hline \multirow{2}{*}{ Content } & $50-$ & $17-$ & \multirow{2}{*}{$\mathrm{Bal}$} & $4.75-5.5$ & $2.8-$ & $0.65-$ & $0.2-$ \\
& $55 \%$ & $21 \%$ & & $\frac{\circ}{\circ}$ & $3.33 \circ$ & $1.15 \%$ & $0.8 \%$ \\
\hline
\end{tabular}

Table 2 Properties of Electrodes

\begin{tabular}{|c|c|c|}
\hline Property & Copper & Brass \\
\hline Melting range $\left({ }^{0} \mathrm{C}\right)$ & $1065-1083$ & $885-900$ \\
\hline Density $\left(\mathrm{g} / \mathrm{cm}^{3}\right)$ & 8.94 & 8.49 \\
\hline Thermal conductivity $(\mathrm{W} / \mathrm{m}-\mathrm{k})$ & 388 & 109 \\
\hline Specific heat $(\mathrm{J} / \mathrm{kg} \mathrm{K})$ & 385 & 380 \\
\hline Thermal expansion co-efficient $\left(1 /{ }^{0} \mathrm{C}\right)$ & $16.7 \times 10^{-6}$ & $18.7 \times 10^{-6}$ \\
\hline
\end{tabular}

\section{Methodology}

Design of Experiment (DOE) is an efficient experiment planning process that allows the data obtained to be analyzed, valid conclusions to be drawn and objectives to be set. There are two aspects of any experimental problem, the design of experiment and statistical analysis. Experimental design involves planning experiments to obtain the maximum amount of information from available resources.

DOE is used to determine the appropriate number of tests and the experimental conditions necessary to obtain the desired goal to analyze which factor of the process influences the response variables. The most common design consists of running the test with all the possible combinations of variables at predetermined levels. A well-planned design of experiment can substantially reduce the number of experiments and for this reason a small CCD with three levels was selected to develop the model. In present work, experiments were designed on the basis of experimental design technique using response surface design method. The main idea of RSM is to use a set of designed experiments to obtain an optimal response. The Minitab 16 software was used to analyze the data.

\section{Results and Discussion}

Analysis of variance technique (ANOVA) is carried with Minitab 16. Value of $\mathrm{P}$ is used to determine whether a factor is significant; typically compare against an alpha value of 0.05 . If the p-value is lower than 0.05 , then the factor is significant. From the ANOVA table 4 and table 5 it is conclude that the current and pulse on time are most significant while voltage is less significant for MMR and TWR for both the electrodes respectively.

\subsection{Effect of Current (C) on MRR and TWR}

The current depends on the different power levels that can be supplied by EDM machine generator. It represents maximum value of the discharge current intensity. Figure 1 (a) shows the effect of current on MRR. From figure it is observed that copper and brass electrodes achieve the best MRR with the increase in discharge current.

As compare to copper, brass gives the less MRR at low and high setting of input parameters, but the material removal rate at the middle setting of input parameters is same for both the electrodes. Figure 1 (b) shows the effect of current on TWR. Copper and brass shows a considerably increase in TWR with increase in current. As compare to copper, electrode wear rate is more in brass. After machining it is found that the electrodes are coated with thin layers of carbon. 
Table 3 Experimental Results

\begin{tabular}{|c|c|c|c|c|c|c|c|}
\hline \multirow{2}{*}{$\begin{array}{c}\text { Expt. } \\
\text { No. }\end{array}$} & \multicolumn{3}{|c|}{ Process Parameters } & \multicolumn{4}{c|}{ Response Parameters } \\
\cline { 2 - 8 } & \multirow{2}{*}{$\mathrm{C}$} & $\mathrm{V}$ & \multirow{2}{*}{ Ton } & $\begin{array}{c}\text { MRR } \\
\text { (gram/min) }\end{array}$ & $\begin{array}{c}\text { TWR } \\
\text { (gram/min) }\end{array}$ & $\begin{array}{c}\text { MRR } \\
\text { (gram/min) }\end{array}$ & $\begin{array}{c}\text { TWR } \\
\text { (gram/min) }\end{array}$ \\
\hline 1 & 30 & 100 & 750 & 0.0698 & 0.0142 & 0.0560 & 0.0185 \\
\hline 2 & 40 & 80 & 750 & 0.0798 & 0.0184 & 0.0581 & 0.0208 \\
\hline 3 & 50 & 100 & 750 & 0.0871 & 0.0206 & 0.061 & 0.0232 \\
\hline 4 & 40 & 100 & 500 & 0.0784 & 0.0172 & 0.0577 & 0.0201 \\
\hline 5 & 40 & 100 & 750 & 0.0791 & 0.018 & 0.0579 & 0.0212 \\
\hline 6 & 40 & 120 & 750 & 0.0784 & 0.0178 & 0.058 & 0.0207 \\
\hline 7 & 40 & 100 & 750 & 0.0795 & 0.0183 & 0.0579 & 0.0207 \\
\hline 8 & 40 & 100 & 1000 & 0.0812 & 0.0191 & 0.0588 & 0.0219 \\
\hline 9 & 30 & 120 & 500 & 0.0708 & 0.0148 & 0.0544 & 0.017 \\
\hline 10 & 30 & 80 & 1000 & 0.0739 & 0.0149 & 0.0568 & 0.0195 \\
\hline 11 & 40 & 100 & 750 & 0.0792 & 0.0177 & 0.0579 & 0.0207 \\
\hline 12 & 50 & 80 & 500 & 0.0867 & 0.0198 & 0.0611 & 0.0222 \\
\hline 13 & 40 & 100 & 750 & 0.0783 & 0.0177 & 0.0579 & 0.0212 \\
\hline 14 & 50 & 120 & 1000 & 0.0859 & 0.0221 & 0.0614 & 0.0239 \\
\hline 15 & 40 & 100 & 750 & 0.0782 & 0.0173 & 0.0579 & 0.0212 \\
\hline 16 & 50 & 120 & 500 & 0.0849 & 0.0209 & 0.0604 & 0.0221 \\
\hline 17 & 40 & 100 & 750 & 0.0802 & 0.0174 & 0.0579 & 0.0207 \\
\hline 18 & 30 & 120 & 1000 & 0.0744 & 0.0158 & 0.056 & 0.019 \\
\hline 19 & 40 & 80 & 1000 & 0.0811 & 0.0178 & 0.0587 & 0.0218 \\
\hline 20 & 30 & 80 & 500 & 0.0737 & 0.0142 & 0.0559 & 0.0179 \\
\hline
\end{tabular}

Table 4 ANOVA for MRR

(a) Copper

\begin{tabular}{|c|c|c|c|c|}
\hline Term & Coef & SE Coef & $\mathrm{T}$ & $P$ \\
\hline Const & 0.052512 & 0.002368 & 22.18 & 0 \\
\hline $\mathrm{C}$ & 0.000701 & 0.000036 & 19.7 & 0 \\
\hline V & $\begin{array}{c}- \\
0.000039\end{array}$ & 0.000017 & $\begin{array}{c}- \\
2.338\end{array}$ & 0.033 \\
\hline Ton & 0.000004 & 0.000001 & 2.731 & 0.015 \\
\hline
\end{tabular}

(b) Brass

\begin{tabular}{|c|c|c|c|c|}
\hline Term & Coef & SE Coef & $\mathrm{T}$ & $\mathrm{P}$ \\
\hline Const & 0.047665 & 0.000803 & 59.33 & 0 \\
\hline $\mathrm{C}$ & 0.000265 & 0.000012 & 21.96 & 0 \\
\hline $\mathrm{V}$ & - & 0.000006 & - & 2.672 \\
\hline Ton & 0.000015 & 0.017 \\
\hline
\end{tabular}

Table 5 ANOVA for TWR

(a) Copper

\begin{tabular}{|c|c|c|c|c|}
\hline Term & Coef & SE Coef & $\mathrm{T}$ & $\mathrm{P}$ \\
\hline Const & 0.002285 & 0.000977 & 2.338 & 0.033 \\
\hline $\mathrm{C}$ & 0.000305 & 0.000015 & 20.76 & 0 \\
\hline $\mathrm{V}$ & 0.000016 & 0.000007 & 2.346 & 0.032 \\
\hline Ton & 0.000002 & 0.000001 & 4.208 & 0.001 \\
\hline
\end{tabular}

(b) Brass

\begin{tabular}{|c|c|c|c|c|}
\hline Term & Coef & SE Coef & $\mathrm{T}$ & $\mathrm{P}$ \\
\hline Const & 0.009443 & 0.000542 & 17.41 & 0 \\
\hline $\mathrm{C}$ & 0.000239 & 0.000008 & 29.27 & 0 \\
\hline $\mathrm{V}$ & $\begin{array}{c}- \\
0.000009\end{array}$ & 0.000004 & $\begin{array}{c}- \\
2.353\end{array}$ & 0.032 \\
\hline Ton & 0.000004 & 0 & 11.93 & 0 \\
\hline
\end{tabular}




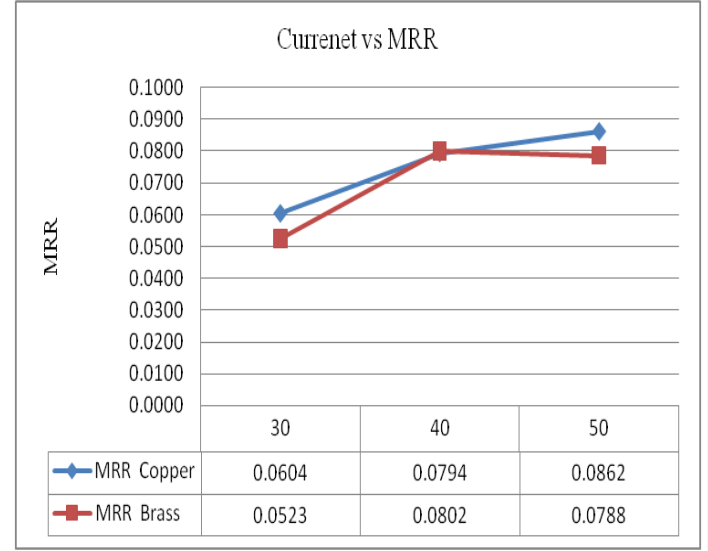

(a)

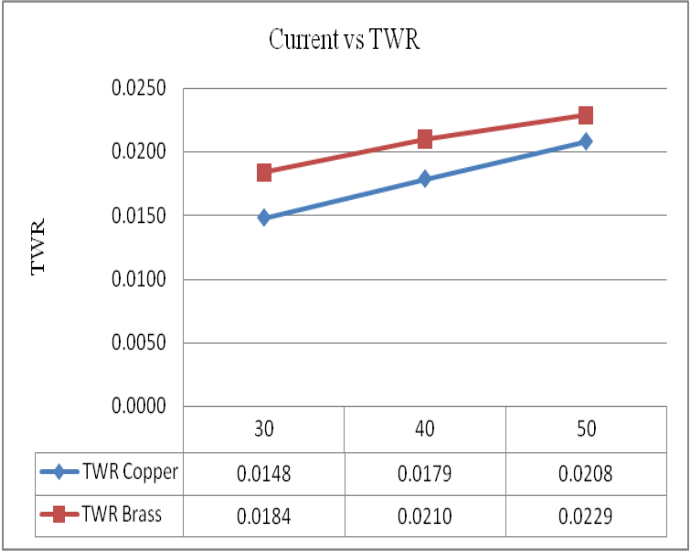

(b)

Fig. 1 Effect of Current on MRR and TWR

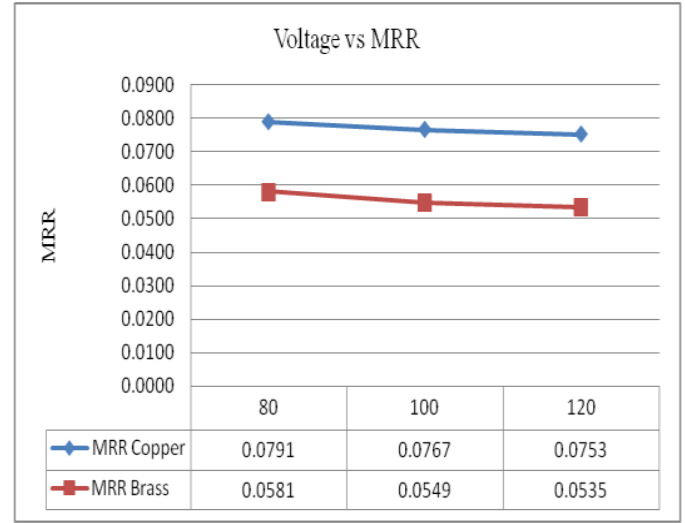

(a)

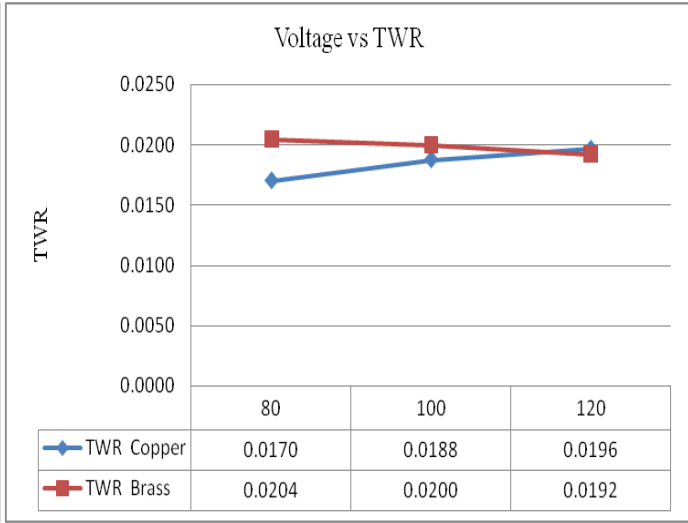

(b)

Fig. 2 Effect of Voltage on MRR and TWR

\subsection{Effect of Voltage (V) on MRR and TWR}

Voltage is the value of electric tension applied between the part to be machined and electrode just before the discharged is produced. Figure 2 (a) shows that value of MRR is highest at the low setting of input voltage and it is decrease as increase in voltage for copper and brass electrode. Investigation shows that the copper gives more MRR than brass.

Figure 2 (b) shows the effect of voltage on TWR. It is found the voltage have considerable effect on TWR, as the voltage increases the tool wear rate also increases for copper electrode. But for brass electrode TWR shows negligible decrease, the specific reason of this decrease in TWR is not found.

\subsection{Effect of Pulse on time (Ton) on MRR and TWR}

Pulse on time is the duration of time (in $\mu$ s) that the current is allow to flow per cycle. It can be noticed that an increase of pulse on time causes the increases in the MRR and TWR for both the electrode as shown in figure 3 (a) and (b). The increase in pulse on time means applying the same heating flux for a longer time. This will cause an increase of heat that is conducted into the workpiece, therefore MRR and TWR increases with increase in pulse on time. The investigation found that copper electrode gives more MRR than brass electrode, so copper electrode is best for MRR. In case of tool wear rate as the pulse on time increases, the TWR also increases for both the electrodes, but it is found that wear is more in case of brass as compare to copper electrode.

\subsection{Optimization}

The figure 4 (a) and (b) shows that the optimizations plot for material removal rate and tool wear rate for copper and brass electrode respectively. The ultimate objective of our work was to maximize the MRR and minimize the TWR. The desirability approach was used for finding out the optimum values of material removal rate and tool wear rate. After investigation it is found that the optimum values of current, voltage and pulse on time are 
$41.72(\mathrm{~A}), 80(\mathrm{~V})$ and $500(\mu \mathrm{s})$ for copper electrode and for brass electrode the optimum values of current, voltage and pulse on time are $41.11(\mathrm{~A}), 80(\mathrm{~V})$ and $500(\mu \mathrm{s})$ respectively.

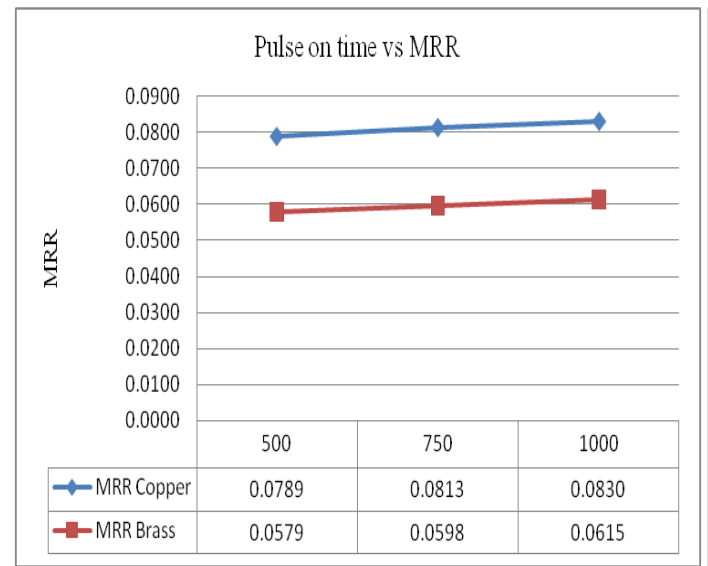

(a)

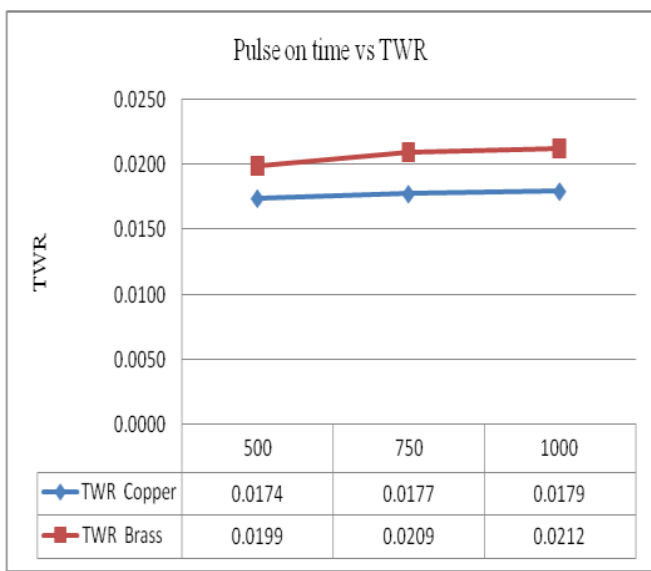

(b)

Fig. 3 Effect of Pulse on time on MRR and TWR

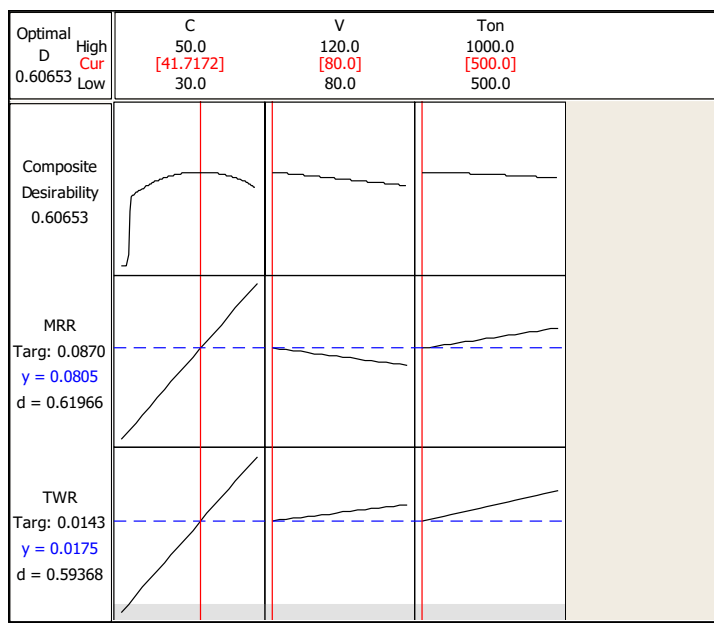

(a) Copper electrode

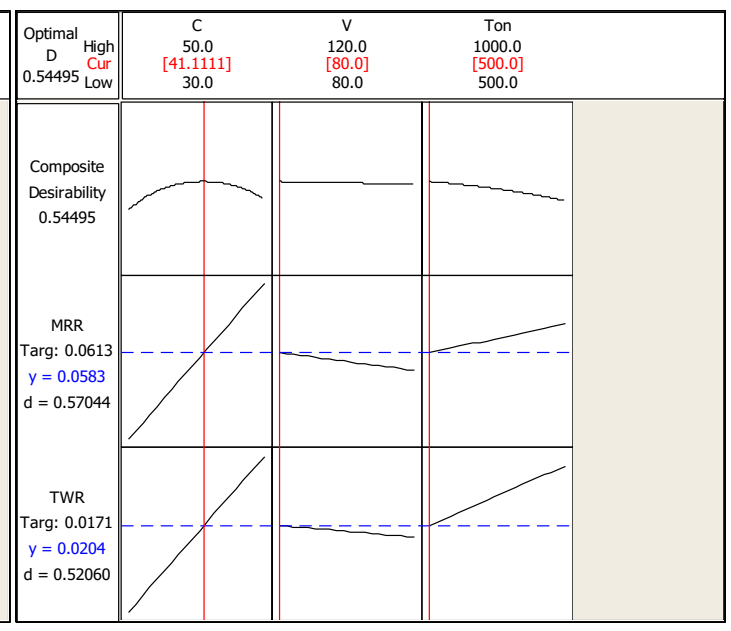

(b) Brass electrode

Fig. 4 Optimization Plot

\subsection{Confirmation Experiments}

The purpose of the confirmation experiment is to validate the conclusions drawn during the analysis phase. After determining the optimum levels, new experiments are designed and conducted with optimum levels of the machining parameters. The following results were found as shown in table 6 .

Table 6 Comparison between Predicted Values and Experimental Values

\begin{tabular}{|c|c|c|c|c|}
\hline Contents & \multicolumn{2}{|c|}{ Copper } & \multicolumn{2}{c|}{ Brass } \\
\hline $\begin{array}{c}\text { Predicted values } \\
\text { (gm/min) }\end{array}$ & MRR & 0.0805 & MRR & 0.0583 \\
\cline { 2 - 5 } & TWR & 0.0175 & TWR & 0.0204 \\
\hline $\begin{array}{c}\text { Experimental } \\
\text { values (gm/min) }\end{array}$ & MRR & 0.0793 & MRR & 0.0568 \\
\cline { 2 - 5 } & TWR & 0.0182 & TWR & 0.0214 \\
\hline \multirow{2}{*}{ Error in $\%$} & MRR & 1.49 & MRR & 2.57 \\
\cline { 2 - 5 } & TWR & 3.84 & TWR & 4.67 \\
\hline
\end{tabular}

The percentage error between the actual and predicted values of the responses fall below $5 \%$, which shows that the optimized values of EDM process parameters obtained are good enough for achieving the target set during 
the experiment. The comparison again shows the good agreement between the predicted and experimental values.

\section{Conclusion}

After analyzing the results of the experiments on Inconel 718 with copper and brass electrode the following conclusions are arrived: Current is most affecting parameter followed by pulse on time for both MRR and TWR. Material removal rate and tool wear rate increases as the current and pulse on time increases. While material removal rate decreases for both the electrodes as increase in voltage and tool wear rate decreases for brass and increases for copper as the voltage increases. Copper electrode offers comparatively low electrode wear while brass wears the most for the tested work material. It is observed that copper electrode perform better than brass for the tested work material. The machining performanance at the predicted process parameters was compared with the actual machining performanance and good agreement was obtained between these performanance.

\section{Acknowledgement}

Authors express their hearty thanks to the Indo-German Tool Room, Aurangabad, India for providing us the facility to carry out the research work and publishing this article.

\section{References}

[1] S.Singh, S. Maheshwari , P.C. Pandey", "Some investigations into the electric discharge machining of hardened tool steel using different electrode materials" Journal of Materials Processing Technology 149 (2004) 272-277.

[2] M.Manohar ${ }^{1}$, T.Selvaraj ${ }^{2}$, D.Sivakumar ${ }^{3}$, S.Gopinath $^{4}$, K.M.George ${ }^{5}$, "Experimental study to assess the effect of Electrode bottom profiles while machining Inconel 718 through EDM Process", Procedia Materials Science 6 (2014) 92- 104

[3] S.H.Lee ${ }^{1}$, X.P.Li " "Study of effect of machining parameters on the machining characterstitics in electric discharge machining on Tungsten carbide", Journal of Material Processing Technology 115(2001) 344-358.

[4] S.S. Habib" "Study of the parameters in electrical discharge machining through response surface methodology approach", Applied Mathematical Modelling 33 (2009) 4397-4407.

[5] C.J. Luis", I. Puertas ${ }^{2}$, G.Villa ${ }^{3}$, "Material removal rate and electrode wear study on the EDM of silicon carbide", Journal of Materials Processing Technology 164-165 (2005) 889-896.

[6] N.Arunkumar ${ }^{1}$, H.S.A.Rawoof ${ }^{2}$, R.Vivek ${ }^{3}$, " Investigation on the Effect Of Process Parameters For Machining Of EN31 (Air Hardened Steel) By EDM”, International Journal of Engineering Research and Applications (IJERA) Vol. 2, Issue4, July-August 2012, pp.1111-1121. 